\title{
Generation of Electrical Power Using Solar Energy and to Design Simple Inverter Circuit with Large Power Output
}

\author{
Vinayak .S. $\mathrm{W}^{1}$, K. M. Kavitha ${ }^{2}$ \\ ${ }^{1}$ Student, Electrical and Electronics Engineering Dept ,AIT College, Chikkamagaluru-577102 Karnataka, India \\ ${ }^{2}$ Adjunct Faculty, Electrical and Electronics Dept., AIT College, Chikkamagaluru-577102 Karnataka, India
}

\begin{abstract}
Energy is the primary and most universal measure of all kinds of work by human beings and nature. Everything what happens in the world is the expression of flow of energy in one of its forms. Among different types of energies electrical energy is most important; because every individual is dependent on electrical energy for the every day's life. It is clean and very convenient and can be transformed from one place to another easily. Today every country is meeting its energy demand by drawing power from a variety of sources. We can broadly categorize these sources as renewable and nonrenewable sources. The renewable sources include: solar energy, wind energy, biomass energy, geothermal energy, tidal energy etc. The non-renewable energy sources include fossil fuels (coal, oil, natural gas), nuclear power. While the non-renewable energy sources will get exhausted eventually in the next century. Therefore we are going for the renewable sources because they do not exhaust, they can be used for long time, freely available from nature, does not affect environment. In recent years, the interesting solar energy has risen due to surging oil prices and environmental concern. In many remote or under developed areas, direct access to an electric grid is not easily possible and therefore photovoltaic inverter system which works on solar energy would make life much simpler and more convenient. With this in mind, this project aims to design, build solar panel inverter. This inverter system could be used as a back-up during power outages, for battery charging and for typical household applications.
\end{abstract}

Keywords: Solar energy, Inverter, MOSFET

\section{Introduction}

Energy is the primary and most universal measure of all kinds of work by human beings and nature. Everything what happens in the world is the expression of flow of energy in one of its forms. Among different types of energies electrical energy is most important; because every individual is dependent on electrical energy for the every day's life. It is clean and very convenient and can be transformed from one place to another easily. Today every country is meeting its energy demand by drawing power from a variety of sources. The non-renewable energy sources include fossil fuels (coal, oil, natural gas), nuclear power. While the non-renewable energy sources will get exhausted eventually in the next century. Therefore generating electrical power using renewable energy sources is must.Among different sources solar energy is available in large quantity and freely. In present days some of the rural areas are suffering due to non-availability of continuous electric power and due to unscheduled load shedding This problem can be overcome by using solar energy.

In general, the energy produced and radiated by the sun, more specifically the term refers to the sun's energy that reaches the earth. Solar energy received in the form of radiation, can be converted directly or indirectly into other forms of energy, such as heat and electricity which can be utilized by man. Since the sun is expected to radiate at an essentially constant rate for a few billion years, it may be regarded as an in-exhaustible source of use full energy. Currently, solar energy is used to provide electricity to homes, businesses organizations, and educational institutes and in space vehicles used by NASA. Because of rise in price of traditional energy, use of solar energy is growing at the rate of 25 percent a year.

\section{Merits of solar energy}

- Solar energy is the main constituent of all the availableenergy sources.

- It can be utilized in almost throughout the year.

- It produces almost negligible environmental pollution.

- It is easily available almost all parts of our country so themachineries based on solar energy is easily accessible.

\section{Objectives}

To generate the electrical power using solar power and to design a simple inverter circuit using MOSFET.

\section{Methodology}

This is a simple project which is easy to build and also cheap, as all the parts are readily available on the market. With average background in engineering, the inverter circuit can be made and used at all times. It can be constructed and used in the villages where there is no proper supply of electricity. The inverter can be transported and used anywhere when necessary.

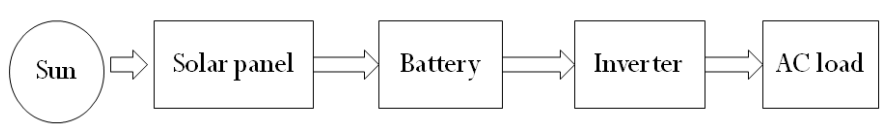

Figure 1: Block diagram 


\section{International Journal of Science and Research (IJSR) \\ ISSN (Online): 2319-7064 \\ Index Copernicus Value (2013): 6.14 | Impact Factor (2015): 6.391}

\subsection{Solar Cell}

A solar cell (also called a photovoltaic cell) is an electrical device that converts the energy of light directly into electricity by the photovoltaic effect. It is a form of photoelectric cell (in that its electrical characteristics e.g. current, voltage, or resistance vary when light is incident upon it) which, when exposed to light, can generate and support an electric current without being attached to any external voltage source.

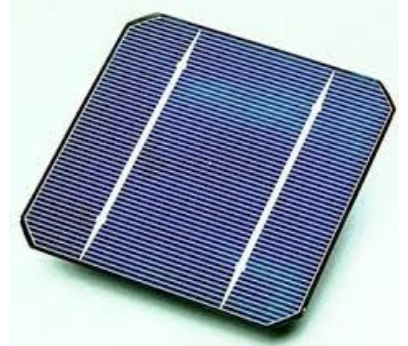

Figure 2: PV cell (photovoltaic cell)

\subsection{Inverter}

In this the most important building block is the inverter block. Inverter converts the D.C voltage in to A.C. An inverter must be designed to supply a voltage of 240 volt to domestic loads. The inverter in this project converts the 12 $\mathrm{DC}$ voltage to 240 volt AC voltage. Only very large systems over 3,000 watts will use a 240 volt inverter to power both 240 and 120 volt loads.

The inverter circuit is divided into two major functional blocks: the multivibrator stage and inverter stage. The multivibrator stage generates the pulses to the output during each switching cycle, while the inverter stage inverts the pulsating signals into sine waves using four complementary field effect transistors to be amplified by the center tapped transformer to produce $230 \mathrm{~V}$ AC.

\subsection{Batteries}

Essentially, a battery consists of one or more cells connected in series to give the required voltage. A battery provides a voltage source that has a small internal resistance. The capacity of a battery is expressed in watts - hour (Wh). The product of the capacity and the voltage of a battery and its amount of energy are expressed in ampere - hour (Ah).

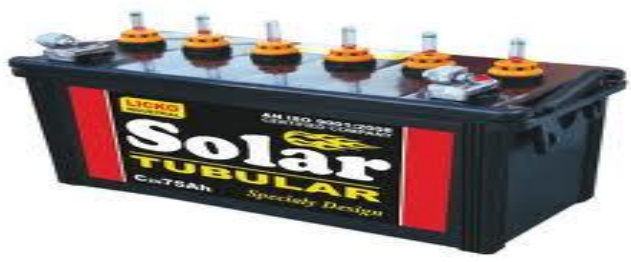

Figure 3: Solar battery

These three parameters vary with both temperature and the rate of discharge. Immediately a current is taken from the battery, there is a voltage drop across its internal resistance and the terminal voltage drops to the plateau value. The larger the current taken from the battery, the smaller will be the plateau voltage. The open - circuit voltage may be larger than the nominal voltage by as much as $15 \%$. When the battery is exhausted its terminal voltage rapidly falls to a low value and thus need to be replaced or recharged.

The batteries must be capable of storing and supplying the proper power to the inverter. You will need to use 12 volt batteries or two 6 volt batteries in series to get 12 volts. The number of batteries needed depends on the size of the solar system, inverter, and load desired to supply.

\section{IC Based Inverter design}

A 500W PWM inverter circuit built around IC SG3524 is shown here. SG3524 is an integrated switching regulator circuit that has all essential circuitry required for making a switching regulator in single ended or push-pull mode. The built in circuitries inside the SG3524 include pulse width modulator, oscillator, voltage reference, error amplifier, overload protection circuit, output drivers etc. SG3524 forms the heart of this PWM inverter circuit which can correct its output voltage against the variations in the output load. In a non PWM inverter the change in output load directly affects the output voltage (when output load increases output voltage decreases and vice versa), but in a PWM inverter the output voltage remains constant over a range of output load.

\subsection{Description about circuit}

Equivalent resistor and capacitor sets the frequency of the ICs internal oscillator. Preset resistor can be used for fine tuning of the oscillator frequency. Pin 14 and pin 11 are the emitter terminals of the internal driver transistor of the IC. The collector terminals of the driver transistors (pin 13 and 12) are tied together and connected to the $+8 \mathrm{~V}$ rail (output of the 7809). Two $50 \mathrm{~Hz}$ pulse trains which are 180 degree out of phase are available at pin 14 and 15 of the IC. These are the signals which drive the subsequent transistor stages.

When signal at pin 14 is high, MOSFET 1 is switched on, are current flows from the $+12 \mathrm{~V}$ source (battery) connected at point a (marked with label a) through the upper half of the transformer (T1) primary and sinks to ground through the MOSFET 2. As a result a voltage is induced in the transformer secondary (due to electromagneticinduction) and this voltage contributes to the upper half cycle of the $220 \mathrm{~V}$ output waveform. During this period pin 11 will be low and its succeeding stages will be inactive. When 11 of the IC pin goes high MOSFET 2 gets switched ON . Current flows from the $+12 \mathrm{~V}$ source (marked with label a) through the lower half of the transformer primary and sinks to the ground through MOSFET 1 and the resultant voltage induced at the T2 secondary contributes to the lower half cycle of the $220 \mathrm{~V}$ output wave form.

\section{Results}

The output across various stages of the circuit is connected to the CRO and the output is taken and is shown below. The output across the power MOSFET is given to the center tap transformer at the primary it as 12-0-12 volts and at the secondary it has $230 \mathrm{~V} 50 \mathrm{~Hz}$ which is further connected to various kind of loads.

\section{Volume 5 Issue 5, May 2016}




\section{International Journal of Science and Research (IJSR) \\ ISSN (Online): 2319-7064}

Index Copernicus Value (2013): 6.14 | Impact Factor (2015): 6.391

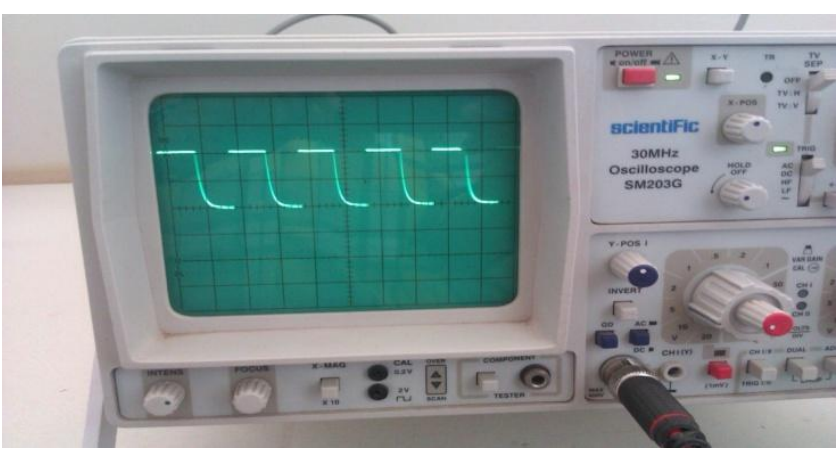

Figure 4: Output of Astable Multiviberator

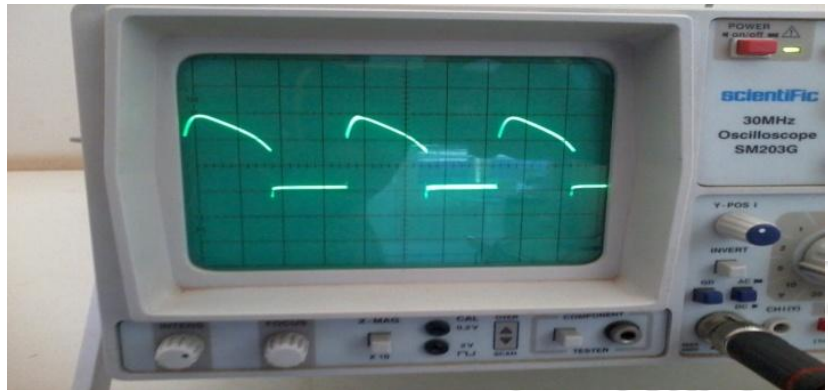

Figure 5: Output across power MOSFET

\section{Conclusion}

From this project we are able to design inverter of capacity $500 \mathrm{~W}$ to supply load of $200 \mathrm{~W}$ lighting and $300 \mathrm{~W}$ fan load using solar energy. Hence after carrying out this project, we conclude that using solar energy with proper battery and inverter circuit one can easily, continuously supply the lighting and fan loads.

\section{Future Work}

This project can be extended to supply entire light and fan loads ofthe dept. and college.Can be extended to supply other types of loads such as Computer, Projector, laptops, Solder gun etc. Can be effectively implemented in each and every house in rural areas.

\section{References}

[1] Nonconventional energy sources by G.D.Rai

[2] Analog electronic circuits by Devid Bell.

[3] Modern Power electronics by Chitthod.

[4] Butti, Ken; Perlin, John (1981). A Golden Thread (2500 Years of Solar Architecture and Technology). Van Nostrand Reinhold.

[5] Carr, Donald E. (1976). Energy \& the Earth Machine. W. W. Norton \& Company.

[6] Halacy, Daniel (1973). The Coming Age of Solar Energy. Harper and Row.

[7] Martin, Christopher L.; Goswami, D. Yogi (2005). Solar Energy Pocket Reference. International Solar Energy Society.

[8] Mills, David (2004). "Advances in solar thermal electricity technology".

[9] Perlin, John (1999). From Space to Earth (The Story of Solar Electricity). Harvard University Press. 